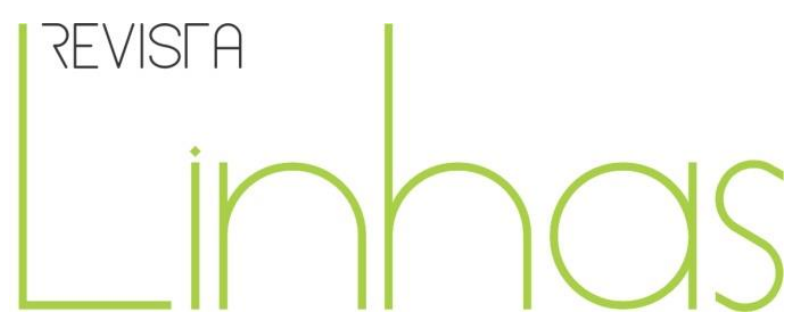

\title{
Biblioteca de orientação da Professôra Primária do Programa de Assistência Brasileiro-Americana ao Ensino Elementar - PABAEE (1956-1964)
}

\begin{abstract}
Resumo
Este estudo pretende apresentar o conjunto de manuais que compõem a Coleção Biblioteca de Orientação da Professôra Primária, fruto do Programa de Assistência Brasileiro-Americana ao Ensino Elementar (PABAEE), a fim de oferecer novas possibilidades de pesquisa sobre a produção realizada no interior do programa. $O$ PABAEE ocorreu durante os anos de 1956 a 1964, decorrente do convênio estabelecido entre o governo brasileiro (Juscelino Kubitschek - 1956 a 1961) e o governo dos Estados Unidos. A coleção de manuais foi elaborada para o aperfeiçoamento das professoras primárias, para que viessem a pôr em prática novas metodologias consideradas modernas, inspiradas pela Escola Nova e que tiveram ampla circulação no território brasileiro durante os anos de existência do programa.
\end{abstract}

Palavras-chave: Programa de Assistência Brasileiro-Americana ao Ensino Elementar. Professores de Ensino Primário. Manuais Escolares.

\author{
Susane Costa Waschinewski \\ Universidade do Extremo Sul \\ Catarinense - UNESC - \\ Criciúma/SC - Brasil \\ sucosta@unesc.net \\ Giani Rabelo \\ Universidade do Extremo Sul \\ Catarinense - UNESC - \\ Criciúma/SC - Brasil \\ gra@unesc.net
}

\footnotetext{
Para citar este artigo:

WASCHINEWSKI, Susane Costa; RABELO, Giani. Biblioteca de orientação da Professôra Primária do Programa de Assistência Brasileiro-Americana ao Ensino Elementar - PABAEE (1956-1964). Revista Linhas. Florianópolis, v. 19, n. 39, p. 286-314, jan./abr. 2018.
} 


\title{
Library of orientation of the Primary Profession of the Brazilian-American Assistance Program to Elementar - PABAEE Teaching (1956-1964)
}

\begin{abstract}
This study intends to present the set of manuals that compose the Library of Orientation Library of the Primary Professorship of the Brazilian-American Assistance Program for Elementary Education (PABAEE), in order to offer new possibilities of research on the production carried out inside the program. The PABAEE occurred during the years 1956 to 1964, resulting from the agreement established between the Brazilian government (Juscelino Kubitschek - 1956 to 1961) and the government of the United States. The manual collection was developed for the improvement of the primary teachers, so that they could implement new methodologies considered modern, inspired by the New School and that had wide circulation in the Brazilian territory during the years of existence of the program.
\end{abstract}

Keywords: Brazilian-American Assistance Program for Elementary Education. Teachers of Primary Education. School Manuals. 


\section{Introdução}

O processo de institucionalização da escola no Brasil se intensificou com a produção da cultura material escolar (SILVA; PETRY, 2011), por meio de materiais pedagógicos como cadernos, manuais, vestuário, mobiliários, produzindo e sendo produzidos por uma cultura escolar.

Nesse sentido, os manuais escolares são compreendidos como importantes fontes de pesquisa para o campo da História da Educação, pois nos ajudam a compreender as normatizações das atividades de ensino, presentes no cotidiano escolar, bem como o direcionamento para a construção do comportamento dos/as professores/as e seus alunos/as.

O patrimônio cultural escolar tem despertado, nos últimos anos, o interesse de muitos/as pesquisadores/as da história da educação, principalmente em relação manuais escolares. Isso, segundo Choppin (2009), tem ocorrido devido a sua má conservação e seu constante descarte, raramente inventariado, dificultando o acesso dos pesquisadores ${ }^{1}$.

Realizar uma definição do que é o Manual Escolar não é uma tarefa simples e se constitui de um importante debate no campo da História da Educação. Choppin (2009) aborda os diferentes aspectos da história dos manuais escolares no mundo, como: os vocábulos utilizados para designar o manual escolar; a delimitação do conceito que difere os manuais de outras categorias editoriais; o suporte do manual e suas modalidades de difusão e de utilização e, por último, os problemas metodológicos e as questões ligadas à categorização e à tipologia, a fim de poder compreender o manual escolar de acordo com sua época.

Mediante tais considerações, procuramos entender o manual destinado às professoras primárias como um conjunto de prescrições para o desenvolvimento de uma nova metodologia de ensino.

\footnotetext{
${ }^{1}$ No Brasil há muitos trabalhos sobre cultura material escolar/manuais, inclusive, em Santa Catarina e no Rio Grande do Sul, podemos citar as seguintes pesquisadoras: Vera Lucia Gaspar, Maria Teresa Santos Cunha, Maria Helena Camara Bastos.
} 
As obras destinadas aos professores, quando existem, compreendem, em teoria, duas categorias distintas: a primeira contém os "livros do mestre" ou "livros do professor", que são associados a determinado manual de aluno e que, seguido das disciplinas e das épocas, dá as respostas às questões ou às correções dos exercícios, ou fornece ao professor as pistas para exploração pedagógica ou ainda documentos ou atividades complementares; a segunda integra os livros que tratam de questões pedagógicas (condução da classe...) ou didática (métodos de aprendizagem...) e são utilizados quando da formação inicial dos professores (nesse caso, os mestres estão ainda na posição de aluno, ele podem aprender nos manuais como os outros) ou ao longo de sua vida ativa (aqueles da literatura profissional). (CHOPPIN, 2009, p. 54-55)

Podemos considerar também que a materialidade presente nos manuais escolares está imbricada em diferentes esferas, não apenas nos modos de produção, mas de reprodução/produção e em seu consumo. Constituindo-se, assim, em uma fonte complexa, em que se faz necessária uma imersão no contexto histórico, não apenas para compreender a sua disseminação, mas como forma de compreensão de sua própria existência. Repleta de ausências, a história dos manuais no Brasil é análoga às mudanças da sociedade.

Nesse sentido, o objetivo deste artigo é apresentar os manuais escolares da coleção Biblioteca de Orientação da Professôra Primária ${ }^{2}$ que faz parte do acervo didático produzido no Programa de Assistência Brasileiro-Americana ao Ensino Elementar (PABAEE), a fim de oferecer novas possibilidades de pesquisa sobre esses documentos que foram produzidos no referido Programa, enquanto fonte e ou objeto de pesquisa.

Propor o estudo do manual escolar não é uma tarefa fácil, pois ao passo que temos uma fonte privilegiada, temos uma dupla dimensão objeto e fonte, como afirmam Ana Maria de Oliveira Galvão e Antonio Augusto Gomes Batista (2003), o que nos deixa na iminência de assumir o discurso da fonte ou realizar uma análise muito descritiva. Diante da perspectiva da história cultural, da qual nos encontramos afiliadas, propomos que o manual escolar seja visto como um meio pedagógico didático (informações, disciplina, verdade), constituindo-se em uma importante fonte sobre a cultura escolar e a sociabilidade escolar (MAGALHÃES, 2008).

\footnotetext{
${ }^{2}$ Neste artigo, optamos em manter grafia original da época do título da coleção e de seus manuais.
} 
Antes de focar a coleção, traçaremos uma breve apresentação do Programa, abrangendo seus objetivos e o seu alcance no território brasileiro, a fim de compreender o processo de circulação das ideias pedagógicas apresentadas pelo Programa em questão.

O PABAEE ocorreu entre os anos 1956-1964, no período conhecido como desenvolvimentista, durante o governo de Juscelino Kubitschek (1956 a 1961). A realização do acordo firmado entre Brasil e Estados Unidos (EUA) tinha como objetivo reduzir os índices de evasão e repetência das escolas primárias brasileiras, contribuindo assim para a melhoria das questões educacionais no país.

Em meio ao contexto da Guerra Fria, foi possível perceber que os países denominados periféricos tornaram-se alvos da atenção dos Estados Unidos. Desse modo, foi lançada uma série de programas de ajuda econômica, que visavam ao desenvolvimento desses países, mediante o apoio político, cultural e econômico.

O convênio que criou a coleção Biblioteca de Orientação a Professôra Primária do PABAEE foi parte de um dos muitos convênios estabelecidos entre o Ministério de Educação e Cultura (MEC), em parceria com Instituto Nacional de Estudos Pedagógicos $(\text { INEP) })^{3}$, e organismos internacionais, como a United States Operation Missionto Brazil (USOM), que estava baseada na ideia de ajuda aos países "subdesenvolvidos" inseridos nas políticas da chamada Doutrina Truman.

Segundo Paiva e Paixão (2002), a realização do PABAEE surgiu a partir do Ponto IV da Doutrina Truman, que objetivava a segurança nacional em uma firme política contra a expansão do socialismo soviético. O presidente dos Estados Unidos Harry Truman (1945 1953) proferiu em discurso de posse de seu segundo mandato quatro pontos fundamentais para a condução da política externa do seu país. Os três primeiros pontos eram reafirmações de políticas já adotadas em seu primeiro mandato; já no quarto ponto, Truman afirma que:

Devemos pôr em execução um novo programa audaz, para que os benefícios de nossos avanços científicos e progresso industrial sejam colocados à disposição do melhoramento e crescimento das regiões 
subdesenvolvidas. [...] acredito que temos de colocar à disposição dos povos amantes da paz os benefícios de nosso acervo de conhecimento técnico, a fim de ajudá-los a realizar suas aspirações para uma vida melhor. E, em cooperação com outras nações, devemos fomentar o investimento de capital nas regiões que necessitam de desenvolvimento [...]. (TRUMAN apud BLACK, 1968, p. 28)

Nesse discurso fica declarada a política dos Estados Unidos de ajuda às áreas economicamente subdesenvolvidas. É a partir, então, do Programa Ponto IV que foram previstos inúmeros desígnios de assistências técnicas aos países latino-americanos, sendo um dos resultados dessa política o PABAEE.

Circunscrito nesse contexto, o PABAEE gerou muitas polêmicas, o que dificultou a aceitação do programa nos primeiros anos de funcionamento. Entre as desconfianças que o rondavam estavam as críticas dos que acreditavam que a presença de técnicos vindos dos Estados Unidos poderia pôr em risco a cultura brasileira e, em especial, a do povo mineiro, pois a sede do PABAEE foi instalada na cidade de Belo Horizonte.

Os que se posicionavam favoráveis ao PABAEE acreditavam que ele era de grande ajuda para o ensino primário brasileiro, pois viam nos Estados Unidos um modelo educacional inovador e que estava dando certo. De acordo com Paiva e Paixão (2002), a ala que mais combateu o programa foi a da Igreja Católica, que via no programa uma ameaça com a importação da pedagogia pragmatista de Dewey e as ideias de laicização do ensino, que no olhar dos católicos não estava em harmonia com os propósitos do ensino brasileiro. Além disso, havia uma preocupação pautada no entendimento de que, com a ajuda do programa, o ensino da escola pública pudesse se tornar mais atraente do que o ensino oferecido pelas escolas confessionais.

Outras oposições também se constituíram referentes aos métodos de ensino, criando certo clima de hostilidade entre os/as técnicos/as do programa e as professoras do Instituto de Educação de Belo Horizonte (MG), sede do programa. De acordo com Paiva e Paixão (2002), a oposição tomava como referência os métodos de alfabetização 
utilizados e defendidos pela professora Lúcia Casasanta ${ }^{4}$, que se diferenciava das novas metodologias propostas pelo PABAEE.

Um acontecimento que aumentou ainda mais a hostilidade entre as professoras primárias e os técnicos do Programa, ocorreu com o lançamento do filme "A escola agora é outra" como material de divulgação do PABAEE. O filme, com duração de 10 minutos e 37 segundos, teve como objetivo divulgar o Programa nos cursos de aperfeiçoamento oferecidos em todo o território nacional, entretanto, o conteúdo do filme foi alvo de denúncias por parte das professoras. A primeira parte do filme apresenta a escola com crianças desinteressadas, professoras sem controle sobre a turma, e aulas pouco atrativas, ou seja, representa a escola como um verdadeiro caos, crianças correndo, desrespeitando as professoras, entre outras situações. Já na segunda parte do filme, com a visita dos técnicos do PABAEE, as professoras aprenderam novas metodologias de ensino e instruções para realizar seu trabalho pedagógico. Assim, o filme termina com as crianças atentas realizando as atividades e as professoras felizes. As professoras denunciaram que aquelas cenas teriam sido preparadas e que não representavam a realidade educacional das escolas mineiras.

Além de ter demonstrado o PABAEE como uma solução para os problemas educacionais, apresentou a professora com uma responsável pelo sucesso do sistema educacional, cabendo a ela a formação de seus/suas alunos/as com o intuito de serem cidadãos do futuro. Importante lembrar que os anos de 1950 evidenciam mudanças econômicas rumo à industrialização, modernização e desenvolvimento do país. Nesse sentido, a escola tradicional, baseada nos mesmos métodos tradicionais, passou a ser considerada, por muitos intelectuais, ineficaz para a nova etapa que o país vivenciava. É neste cenário que o PABAEE entra, apresentando inovações pedagógicas consideradas pelas autoridades educacionais necessárias para reestruturar o ensino primário brasileiro, tornando-o mais prático e capaz de formar cidadãos modernos.

\footnotetext{
${ }^{4}$ Esposa de Mário Casasanta (diretor do Instituto de Educação de Minas Gerais), Lúcia Casasanta, como professora da Escola de Aperfeiçoamento, que mais tarde passou a ser Curso de Administração Escolar, teve influência considerável na qualificação dos supervisores de ensino mineiros e na divulgação do método global, abordagem que defendia de acordo com a qual escreveu e publicou material didático para alfabetização largamente utilizado nas escolas primárias mineiras (PAIXÃO, 2002).
} 


\section{PABAEE: instrução para o ensino prático e a formação da professora primária}

Na década de 1950, em meio à efervescência provocada pelos discursos nacionais desenvolvimentistas e com a participação de intelectuais renovadores em cargos da administração pública, as políticas educacionais defendidas pelos escolanovistas passam do campo teórico para o exercício de experimentação em algumas escolas brasileiras. Em razão disso, houve maior ênfase na formação de professores/as, devido à nova concepção de escola que precisava de professores/as que se articulassem com formas mais dinâmicas do ensino. Nesse momento, a presença feminina do magistério já contava com maior número em relação à atuação dos homens.

Por meio de muitos dispositivos e das práticas incorporadas, foi se criando um jeito de ser professor $a^{5}$ normalista sempre de acordo com os discursos oficiais. Ser professora exigia construir uma representação, que em princípio estava pautada na imagem da mulher séria e recatada, construída em uma postura fechada e discreta. As professoras normalistas eram as jovens que estudavam na Escola Normal (o que compreendia o ensino secundário) e, após concluírem o ensino normal se tornavam professoras dos primeiros anos do ensino elementar. As escolas normais tinham como objetivo a formação de professores. De acordo com Maria das Dores Daros (2005), as escolas normais serviam para capacitar aqueles que atuavam como professores, mas também era aberta a outros que tivessem interesse.

$\mathrm{Na}$ medida em que as mudanças eram incorporadas na organização do ensino, estas repercutiam no campo pedagógico e nas representações de professora. Ser professora normalista significava também atender a discursos oficiais e se moldar aos projetos educacionais e de sociedade que se almejava. O exemplo disso é a existência das disciplinas de psicologia, puericultura e higiene no currículo das escolas normais.

Para Louro (2008), esses novos campos do conhecimento estavam ganhando atenção, pois passaram a mostrar como ocorria o desenvolvimento normal das crianças e quais as formas mais adequadas e modernas de tratá-las. Esses novos conhecimentos sobre alimentação, higiene e doenças compunham as mais recentes descobertas e

\footnotetext{
${ }^{5}$ Louro (1997, p. 461).
} 
conceitos científicos à época. Essas descobertas constituíam-se também em novas formas de controle social, ao passo que a sociedade se tornaria mais complexa.

Buscava-se estabelecer um novo modelo social e mecanismos para que os sujeitos pudessem se autogovernar; neste cenário, a infância torna-se alvo preferencial desse discurso oficial, ou seja, mais que educar, a professora tinha também como responsabilidade proliferar discursos que prescrevessem o autocontrole. Contudo, não significa dizer que não houve resistências, mesmo com tantas orientações e normatizações, as professoras certamente subvertiam as regras, modificando as tarefas prontas, introduzindo seus próprios modos de ensino.

A professora como formadora de muitas crianças e jovens passou a ser alvo central dos programas oficiais e vista como propulsora de uma sociedade que almejava a modernidade e a necessidade de instrução para tal. Segundo Teive (2008, p. 56): “Mais que alfabetizar elas inculcavam saberes relacionados à noção de progresso, produzindo uma nova consciência cívica. Ela instruía e educava, colocando em prática as estruturas fundamentais do ideário escolar republicano".

Em um cenário marcado pelo fim da Segunda Guerra Mundial e consequentes derrotas dos regimes nazifascistas, no Brasil, concomitante, ocorria o fim do Estado Novo, em 1945, e a deposição de Getúlio Vargas, em outubro do mesmo ano. Estes acontecimentos traçariam novos rumos políticos para o país, os quais tinham como objetivo a redemocratização do ensino.

Com o intuito de alcançar tal objetivo era necessário pensar na formação de professores/as e nas novas diretrizes para a organização do ensino. Diante disso, em 1946, é promulgada a Lei Orgânica do Ensino Normal, que em linhas gerais ordenaria todo o ensino normal no país. De acordo com Maria Elizabete Xavier (1994), a lei orgânica do ensino normal e a lei orgânica do ensino primário foram promulgadas no mesmo dia e apresentaram efeitos administrativos que previam normas para a implantação desse ramo de ensino em território nacional. De acordo com o artigo $1^{\circ}$, o ensino normal ${ }^{6}$, ramo de ensino do segundo grau, possui os seguintes objetivos:

\footnotetext{
6 Decreto-lei $n^{\circ} 8.530$, de 2 de janeiro de 1946. Disponível em: <http://www2.camara.leg.br/legin/fed/declei/1940-1949/decreto-lei-8530-2-janeiro-1946-458443publicacaooriginal-1-pe.html>.
} 
1. Prover à formação do pessoal docente necessário às escolas primárias.

2. Habilitar administradores escolares destinados às mesmas escolas. 3. Desenvolver e propagar os conhecimentos e técnicas relativas à educação da infância.

De acordo com o capítulo 2 do mesmo decreto-lei, o ensino normal seria organizado em dois ciclos, sendo o primeiro destinado ao curso de regentes de ensino primário, com a duração de quatro anos e, o segundo, o curso de formação de professores primários, sendo necessários três anos.

O Curso Normal de primeiro ciclo era destinado aos regentes de ensino primário, tendo duração de quatro anos. Ao fim do curso primário, deveria cumprir mais quatro anos destinados à aquisição de conhecimentos das disciplinas de caráter propedêutico como: Português, Matemática, Geografia, História Geral e do Brasil e Ciências Naturais, sendo que apenas no último ano estudavam-se algumas disciplinas de conteúdo pedagógico.

Já o Curso Normal de segundo ciclo formava "mestres primários", com duração de três anos realizados após o Curso Ginasial ou de Regente de Ensino. Esse curso era ministrado nas escolas normais e em institutos de educação.

Durante os anos de 1950 as mudanças em curso intensificaram a expansão do modelo capitalista, ocasionando transformações em diversas áreas, inclusive no campo educacional, mais especificamente no modo de ser professor/a. Essa forma de ser e constituir-se professor/a pode ser compreendida com o auxílio do conceito de representação, a partir dos estudos de Roger Chartier, circunscritos no campo da Nova História Cultural. Para ele:

Trabalhando sobre as lutas de representações, cujo objetivo é a ordenação da própria estrutura social, a história cultural afasta-se sem dúvida de uma dependência demasiado estrita em relação a uma história social fadada apenas ao estudo das lutas econômicas, mas também faz retorno útil sobre o social, já que dedica atenção às estratégias simbólicas que determinam posições e relações e que constroem, para cada classe, grupo ou meio, um "ser-percebido" constitutivo de sua identidade. (CHARTIER, 2002, p. 73) 
Com base nos estudos de História Cultural é possível compreender o ser professor/a contrariando os conceitos positivistas de uniformidade. A representação da professora primária pode ser compreendida não de forma estática, porém composta não de uma, mas por várias identidades e representações.

Durante os anos de 1950, a construção de uma representação de professora primária recebia do novo contexto outros discursos oficiais e que aos poucos constituíam o imaginário do ser professora. Os novos discursos relacionavam-se à ideia de construção do futuro e desenvolvimento da nação. Contudo, esse ideário de ser professora vinha se manifestando desde a educação na república, entretanto nos anos conhecidos como nacional desenvolvimentistas, a figura da professora primária passa a ser central nesse processo.

Associada a um novo modelo de mulher, a professora moderna deveria possuir formação para o exercício da sua função, instruir uma nação que tinha um encontro com o desenvolvimento e a modernização. Essa se constituiu em sua nova missão: formar uma nação de cidadãos para a pátria. A figura que se construía em torno do ser professora agora estava embasada em outras ideias. De acordo com Angela Maria de Souza Martins (1996), após os anos de 1946, com o fim do Estado Novo (1937-1945), havia entre os educadores uma esperança em reviver a proposta educacional implementada por Anísio Teixeira no início da década de 1930, posto que se pretendia reconstruir um modelo que garantisse o caráter científico e democrático, principalmente no que se refere à formação de professores/as.

O professor/a deveria cultivar a curiosidade científica e o interesse humanístico, despertando sua consciência para problemas sociais e morais, possibilitando a formação de um/a novo/a professor/a primário/a que unisse espírito democrático e formação científica (MARTINS, 1996). Desse modo, Anísio propunha que, para se elevar o nível do ensino, era necessário investir na formação de professores/as.

Diante desses elementos, vinha se constituindo outro modo de ser professor/a, alinhado com as novas propostas pedagógicas e com um novo contexto que se desenhava durante os anos de 1950 e 1960. Nesse sentido, os manuais escolares contribuem para compreendermos as exigências a essas representações de professores que vinham se instituindo, principalmente por meio das prescrições feitas para os 
professores/as de como agir, de como e quais conteúdos trabalhar com os alunos/as, o que ler, entre outras indicações. Todas essas recomendações compunham as prescrições que buscavam delinear um novo modo de ser professor/a e, consequentemente, um novo modo de ser aluno/a.

Nessa perspectiva, os manuais escolares contribuíram no processo de construção das novas mentalidades, na medida em que se vivia o entusiasmo da modernização. Todo esse intuito de um novo modo de ser professora primária revela que os manuais, destinados ao aperfeiçoamento das professoras, não eram um simples depósito de conteúdos, mas estavam impregnados de um conjunto de elementos que perpassam o campo do gênero, da moral, da disciplina que, somados, constituíam um conteúdo disciplinador e pronto para formar um novo jeito de ser professora.

A figura da professora primária estava associada aos discursos oficiais; ela era vista como responsável pela formação de muitas crianças e jovens. Era depositada no trabalho dela a expectativa de formação de uma nação moderna que almejava o progresso social. Além da leitura, escrita e o cálculo, a professora primária tinha presente em seu currículo escolar as disciplinas de psicologia, puericultura e higiene. Dessa forma, mais do que ensinar os cálculos e as letras, ela deveria ensinar os preceitos da higiene, as tarefas domésticas e bons modos; assim passa a ser uma figura central nesse novo contexto, e é nesse sentido que eram pautados os cursos de aperfeiçoamento. A coleção Biblioteca de Orientação da Professôra Primária estava circunscrita neste novo cenário, desde as autorias, todos os manuais são elaborados por mulheres, além dos discursos prómodernização que circulam nos textos apresentados pelas autoras.

\section{Coleção Biblioteca de Orientação da Professôra Primária: prescrições de atividades para a escola moderna}

Entre os objetivos do PABAEE estava a elaboração de materiais didáticos para o aperfeiçoamento das professoras primárias, além da tradução e aquisição de novas obras. Tanto as elaborações de livros como a aquisição de novos volumes tinham como objetivo prescrever um ensino mais prático que visasse a soluções de problemas de ensinoaprendizagem. "Elaborar, publicar e adquirir textos didáticos tanto para as Escolas 
Normais como para as Elementares consistia um dos objetivos da assistência" (MINAS GERAIS, 1957 apud PAIVA; PAIXÃO, 2002, p. 35).

Durante a instalação do PABAEE foi criada uma Biblioteca; esse espaço foi destinado para reunir todos os livros, revistas, periódicos, utilizados nos cursos de aperfeiçoamento das professoras. De acordo com Paiva e Paixão (2002), cerca de 10 mil livros sobre moral e pedagogia foram adquiridos. Além dos livros enviados pelos EUA, também foram feitas algumas aquisições em livrarias de Belo Horizonte, totalizando aproximadamente cerca de 20 mil títulos. Além das aquisições foram elaborados novos materiais que tinham por objetivo instrumentalizar as professoras do ensino primário na apreensão de novas técnicas e métodos considerados modernos.

Com o objetivo de disponibilizar materiais elaborados pelo próprio PABAEE, foi criada, no ano de 1964, a Biblioteca de Orientação da Professôra Primária, composta por uma coleção de manuais didáticos, contendo aportes teóricos, metodologias e ilustrações com a finalidade de aperfeiçoar a professora primária para a aquisição das novas técnicas de ensino. A coleção é composta por sete volumes de diferentes áreas. De acordo com as informações contidas nos volumes analisados, foi possível identificar que a edição foi produzida pela Editora Nacional de Direito no ano de 1965. Os manuais foram elaborados por especialistas formados no Curso de Educação Elementar oferecido na Universidade de Indiana (EUA); tal curso teve como objetivo aperfeiçoar as professoras primárias que ministrariam em todo país cursos de aperfeiçoamento realizados pelo PABAEE.

A coleção de manuais tinha como intuito servir como base didática para as professoras primárias, cujo objetivo principal era servir de instrumento para a aquisição da filosofia e das novas técnicas da escola moderna. A coleção é composta pelos seguintes volumes: 
Figura 1- Capas da coleção de manuais Biblioteca de Orientação da Professôra Primária
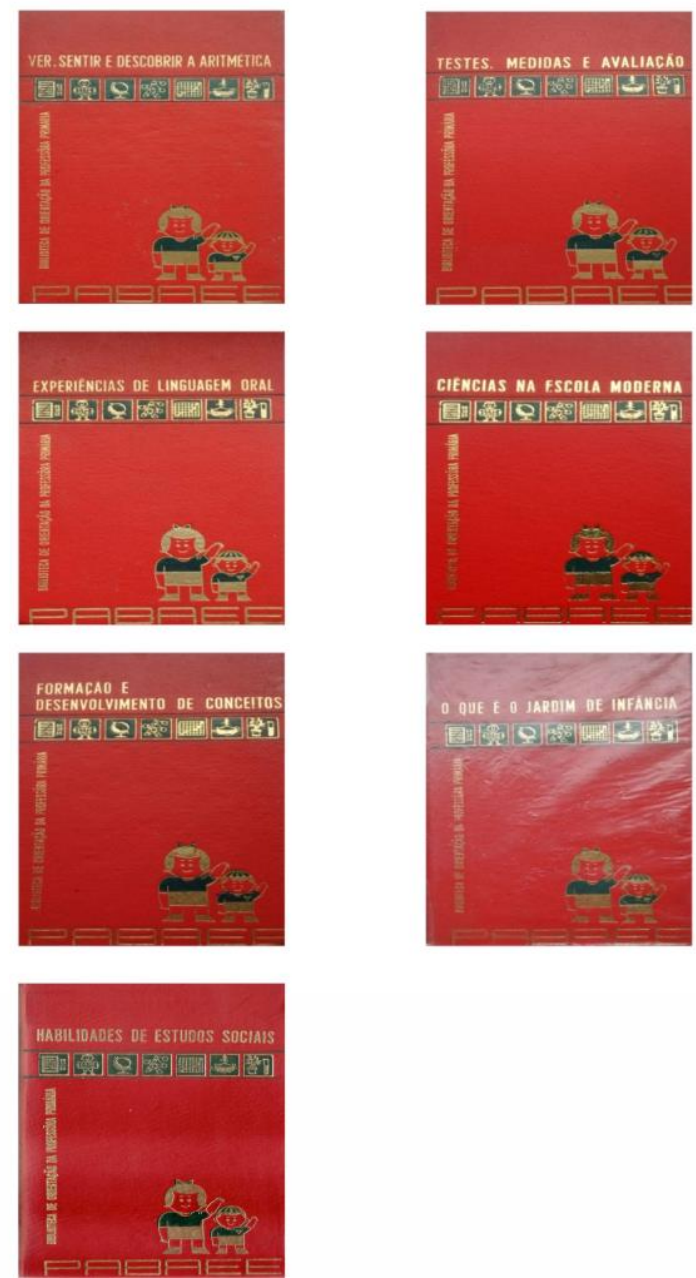

Fonte: Elaborado pela autora (2016), com base na coleção Biblioteca de Orientação da Professôra Primária. Acervo GRUPEHME.

A coleção num todo chama atenção devido ao suporte dos volumes que apresentam certa imponência, pois os manuais possuem capa dura, na cor vermelha com letras douradas, medindo $21,5 \mathrm{~cm}$ de comprimento por $14 \mathrm{~cm}$ de largura. As letras douradas indicam na parte superior a temática do manual, logo abaixo, são expostas figuras que representam cada área de estudo.

Cada manual escolar possui a gravação de uma dessas imagens como, por exemplo, a imagem de um ábaco na capa do volume Ver, sentir, descobrir a Aritmética; a representação de um menino segurando um abecedário na capa do volume intitulado Experiências de Linguagem Oral; o globo terrestre no volume Habilidades de Estudos Sociais, etc. 
Na posição vertical, no lado esquerdo da capa, a escrita indica Biblioteca de Orientação da Professôra Primária. Na parte inferior, à direita, a imagem representa uma professora ao lado de um aluno, seguindo, logo abaixo, está a inscrição das iniciais do programa. Os volumes possuem vinco e lombada, sendo que as páginas são coladas e costuradas. As inscrições na lombada indicam o título do manual e consta também a gravação do símbolo representando a área de estudo. As informações sobre autoria e temáticas dos manuais são apresentadas no quadro abaixo:

Quadro 1 - Livros da Coleção Biblioteca de Orientação da Professôra Primária (1965)

\begin{tabular}{|c|l|l|l|}
\hline \multicolumn{1}{|c|}{ Volume } & Autor (a) & $\begin{array}{l}\text { Editora e Ano da } \\
\text { publicação }\end{array}$ & $\begin{array}{l}\text { Numero } \\
\text { total de } \\
\text { páginas }\end{array}$ \\
\hline $\begin{array}{l}\text { Ver, sentir, descobrir a } \\
\text { Aritimética. }\end{array}$ & $\begin{array}{l}\text { Rizza Araújo Porto com } \\
\text { a colaboração de Evelyn } \\
\text { L. Bull. }\end{array}$ & $\begin{array}{l}\text { Editora Nacional } \\
\text { de Direito, RJ, } \\
1965 .\end{array}$ & $\begin{array}{l}167 \\
\text { páginas }\end{array}$ \\
\hline $\begin{array}{l}\text { Experiências de } \\
\text { Linguagem Oral. }\end{array}$ & $\begin{array}{l}\text { Maria Yvonne Atalécio } \\
\text { de Araújo }\end{array}$ & $\begin{array}{l}\text { Editora Nacional } \\
\text { de Direito, RJ, } \\
1965 .\end{array}$ & $\begin{array}{l}274 \\
\text { páginas }\end{array}$ \\
\hline $\begin{array}{l}\text { Formação e } \\
\text { desenvolvimento de } \\
\text { conceitos. }\end{array}$ & $\begin{array}{l}\text { Maria Luiza de Almeida } \\
\text { Couto Ferreira }\end{array}$ & $\begin{array}{l}\text { Editora Nacional } \\
\text { de Direito, RJ, } \\
1965 .\end{array}$ & $\begin{array}{l}192 \\
\text { páginas }\end{array}$ \\
\hline $\begin{array}{l}\text { O que é Jardim de } \\
\text { Infância. }\end{array}$ & Nazira Feres Abi-Sáber & $\begin{array}{l}\text { Editora Nacional } \\
\text { de Direito, RJ, } \\
1965 .\end{array}$ & $\begin{array}{l}186 \\
\text { páginas }\end{array}$ \\
\hline $\begin{array}{l}\text { Testes, medidas e } \\
\text { avaliação. }\end{array}$ & Oyara Petersen Esteves & $\begin{array}{l}\text { Editora Nacional } \\
\text { de Direito, RJ, } \\
1965 .\end{array}$ & $\begin{array}{l}206 \\
\text { páginas }\end{array}$ \\
\hline $\begin{array}{l}\text { Ciências na Escola } \\
\text { Moderna. }\end{array}$ & Maria José Berutti e & $\begin{array}{l}\text { Editora Nacional } \\
\text { de Direito, RJ, } \\
1965 .\end{array}$ & $\begin{array}{l}279 \\
\text { páginas }\end{array}$ \\
\hline $\begin{array}{l}\text { Habilidades de Estudos } \\
\text { Sociais. }\end{array}$ & Maria Onolita Peixoto & $\begin{array}{l}\text { Editora Nacional } \\
\text { de Direito, RJ, } \\
1965 .\end{array}$ & $\begin{array}{l}186 \\
\text { páginas }\end{array}$ \\
\hline
\end{tabular}

Fonte: Elaborado pela autora (2016), com base na coleção Biblioteca de Orientação da professora primária.

Com o objetivo de compreender um pouco mais os propósitos do PABAEE, buscamos apresentar brevemente cada volume da coleção Biblioteca de Orientação da Professôra Primária e algumas metodologias consideradas inovadoras para os idealizadores do Programa. 


\section{Testes, Medidas e Avaliação}

O volume Testes, Medidas e Avaliação apresenta, em sua introdução, a dificuldade que professores/as, em diferentes épocas, enfrentavam para identificar o nível de conhecimento de seus/suas alunos/as, sendo que a escola moderna não poderia mais ficar presa apenas no julgamento de seus/suas professores/as em relação ao conhecimento de seus alunos/as.

Novas formas de avaliar deveriam ser postas em prática, com objetivos mais precisos e métodos que realmente apresentassem a capacidade intelectual dos alunos/as. O volume tem como autora Oyara Petersen Esteves, Técnica em Educação da Secretaria de Educação do Rio Grande do Sul $\left(\mathrm{CPOE}^{7}\right)$ e Licenciada em Filosofia pela Faculdade de Filosofia do Rio Grande do Sul. Realizou curso de Educação Elementar na Universidade de Indiana - USA, Master of Sciene in Education e era Técnica de Psicologia Educacional do PABAEE. Para Oyara (1965, p. 14), "a escola moderna, entretanto, não visa instruir, dar aos alunos conhecimentos; mas tem como principal objetivo o crescimento e o desenvolvimento de cada aluno em particular, de modo que este se realize de acordo com suas possibilidades".

Nesse sentido, a autora comenta que a preocupação da escola moderna passa a ser a criança num todo e que o uso de instrumentos de medição e avaliações educacionais já era empregado há muito tempo. "Superado o julgamento subjetivo do professor, surgiu nos meios educacionais um movimento no sentido da utilização de medidas mais objetivas - e foi quando os testes passaram a ser empregados em larga escala" (ESTEVES, 1965, p. 14).

No entanto, mais adiante em seu texto, a autora expressa certa preocupação com os limites desses testes, pois nem todos os aspectos poderiam ser submetidos a medidas, como, por exemplo, raciocínio, pensamento crítico e a capacidade de resolver problemas, entre outros. É, então, nesse ponto que a autora propõe a necessidade de apresentar outras medidas, outros testes que possam avaliar o progresso dos alunos. Antes de conhecer um pouco mais da proposta da autora, vejamos como ela organizou seu texto para apresentar suas ideias. Índice; Prefácio; Capítulo I - Introdução; Capítulo II - Conceitos

\footnotetext{
${ }^{7}$ Centro de Pesquisas e Orientação Educacional - CPOE/RS - da Secretaria de Educação e Cultura do Estado do Rio Grande do Sul.
} 
Fundamentais: O que é testar; O que é medir; O que é avaliar; Capítulo III - Característicos Essenciais De Um Bom Instrumento de Medida (Fidedignidade, Validez e outros Característicos); Capítulo IV - Os Testes Propriamente Ditos Mentais (testes de escolaridade, construção dos testes de escolaridade, principais tipos de questões objetivas, provas subjetivas, o que significa os testes); Capítulo V - Medidas Educacionais Em Geral; Outras Técnicas de Avaliação Além dos Testes, Auto Avaliação, Observação do Professor; Capítulo VI - Avaliação Propriamente Dita; Apêndice e Bibliografia.

A autora proporciona um breve histórico sobre os testes mentais, como começaram a entrar em uso em países como França, Inglaterra e Estados Unidos. Ao apresentar as técnicas educacionais mais recentes, identifica uma delas sendo denominado por Binet de QI (coeficiente entre idade mental e idade cronológica), entretanto a autora salienta a importância de estar atento aos resultados desses testes: “[...] alertamos o leitor sobre os cuidados que deve ter ao interpretar os resultados de um teste, e conseqüentemente ao classificar uma criança como tendo este ou aquêle Q.I" (ESTEVES, 1965, p. 69).

Ao longo do manual, Esteves (1965) movimenta muitos autores e modelos de avaliações que podem ser aplicados pelas professoras na escola primária. No tema Principais tipos de Questões Objetivas, a autora apresenta diferentes categorias que podem ser exploradas na avaliação, sendo algumas delas recordação e reconhecimento. Entre estas, chamam atenção as questões de completar, compostas por uma ou mais sentenças, em que algumas palavras ficam omitidas, fazendo com que o aluno lembre das palavras que preenchem os espaços em branco. A autora trabalha também outros exemplos, como verdadeiro e falso, múltipla escolha e ordenação. Sobre todas essas categorias, é interessante destacar que são sempre apresentadas vantagens e desvantagens sobre o seu uso.

\section{Ciências na Escola Moderna}

O manual intitulado Ciências na Escola Moderna trata dos conteúdos e metodologias da disciplina de Ciências, elaborados pelas autoras Maria José Beruti, que cursou Administração Escolar, e Terezinha Nardelli. Ambas foram Técnicas de Didática de 
Ciências Naturais do PABAEE e realizaram o curso de Educação Elementar na Universidade de Indiana (USA).

As autoras apresentam os seguintes assuntos que serão abordados ao longo do manual. Índice; Introdução; Parte I - Considerações sobre o Ensino de Ciências na Escola Elementar, Objetivos do ensino na escola primária; Parte II - Atividades para o estudo de Seres vivos; Atividades para o estudo de Terra e Universo; Atividades para o Estudo de Matéria e Energia; Parte III - Sugestões para confecção de alguns dos materiais necessários ao Estudo de Ciências.

$\mathrm{Na}$ introdução, as autoras comentam que a grande intenção desse volume é ajudar a professora primária na tarefa de fornecer uma ampla base de atividades interessantes e que ajudem os alunos a responder as questões referentes ao ensino da disciplina. No capítulo intitulado Considerações sobre o Ensino das Ciências na escola Elementar, as autoras mencionam a importância do ensino da disciplina:

Não pode, pois ser considerada matéria de menor importância entre as outras do currículo escolar. Isto porque não vai proporcionar, apenas, a aprendizagem de simples fatos científicos, mas, sim, procurar tornar a criança uma pessoa bem informada sobre o mundo que a cerca, capaz de compreender os problemas e de procurar solucioná-los da maneira mais eficiente. (BERUTTI; NARDELLI, 1965, p. 19)

Cabe à professora primária despertar o interesse e demonstrar a importância da disciplina para os alunos, sempre mantendo o equilíbrio entre trabalho e divertimento (BERUTTI; NARDELLI, 1965). Para isso, algumas práticas são sugeridas pelas autoras como, por exemplo, atividades de experimentação, que consistem em descobrir a resposta para alguma questão por meio da observação e do raciocínio, com o objetivo de chegar em resultados após a experimentação completa. As autoras ainda destacam que os materiais a serem utilizados em atividades de experimentação não devem ser muito elaborados, de preferência utensílios simples como martelos, vasos com plantas, arames, fogareiros, pedaços de madeira, entre outros.

O manual chama atenção devido à riqueza de suas ilustrações e detalhes nas prescrições à professora; após as orientações para a realização de atividades práticas 
como experiências e trabalhos em equipes, as autoras sempre descrevem os recursos necessários para a atividade, como deve ser desenvolvido o processo, quais os resultados esperados e, ainda, informações suplementares.

\section{Formação e Desenvolvimento de Conceitos}

O manual intitulado Formação e Desenvolvimento de Conceitos é de autoria de Maria Luíza de Almeida Cunha Ferreira. Ela foi professora de psicologia educacional do PABAEE, com formação em Filosofia (licenciatura) pela Universidade Católica de Minas Gerais (UCMG), instituição em que atuou como professora de Psicologia da Aprendizagem, no Curso de Psicologia. Também trabalhou como professora de História e Filosofia da Educação no curso de formação do Instituto de Educação de Minas Gerais, além de ter realizado curso de Educação Elementar na Universidade de Indiana (EUA), o que a habilitou para trabalhar como Técnica de Psicologia Educacional do PABAEE.

Como podemos observar pela formação da autora e por sua atuação no programa, o manual em questão circula no campo da psicologia da aprendizagem, com o objetivo de oferecer às professoras um material que propõe a reflexão sobre natureza do trabalho mental da criança, processos mentais, influências de fatores emocionais e a relação aprender e compreender. Para propor o estudo dessa temática, Ferreira (1965) dividiu o texto em três capítulos, sendo que esses tratam especificamente: Capítulo I - O Que São Conceitos e Como Se Desenvolvem; Capítulo - II Fatores que Afetam a Aquisição de Conceitos; Capítulo III - Aprender e Compreender.

Para a autora, toda criança nasce em um mundo novo repleto de uma imensa confusão; é no decorrer de um lento processo que essa criança vai começar a perceber e a interpretar o ambiente. "A formação de conceitos é uma das formas de organização que maior papel desempenha na interpretação da experiência" (FERREIRA, 1965, p. 21). Nesse sentido, a proposta de estudo demonstra a importância de compreender a formação de conceitos para as crianças, pois para Ferreira (1965) toda aprendizagem escolar está baseada nos conceitos previamente construídos. "A criança que ingressa na escola primária já possui um repertório de centenas e centenas de conceitos, que representam sua maneira de dar significação aos fatos e acontecimentos" (FERREIRA, 1965, p. 24). 
Nessa perspectiva, o referido manual tem como objetivo instrumentalizar as professoras primárias oferecendo uma base teórica sobre psicologia que possa auxiliar no entendimento sobre o desenvolvimento da criança e a psicologia da aprendizagem.

\section{Ver, Sentir e Descobrir a Aritmética}

O manual Ver, Sentir e Descobrir Aritmética reúne temas, conceitos e atividades sobre o ensino de Aritmética com o objetivo de tornar o ensino mais prático e apropriado para as crianças no ensino primário, sendo esse o grande desafio da disciplina, segundo a professora autora.

Elaborado por Rizza Araújo Pôrto, com a colaboração de Evelyn L. Bull, o manual é composto por introdução e três capítulos subdivididos da seguinte forma: Índice, Prefácio e Introdução. Parte I - A Sala de Aula, Um Laboratório de Aprendizagem, Oportunidades para o uso de Material, Técnicas para o uso do material; Parte II - Discos para Contagem, Mostradores de fatos, Calculadores, Flanelógrafo, Caixa valor do lugar, Ábaco modernizado, Contador de dez dezenas, Ábaco contador, Quadro de vinte, Quadro de cem, Parte de fracionárias, Quadro de frações, medidas; Parte III - Cartazes, confecção, tipos de cartazes; Conclusão e Bibliografia.

Segundo a autora, o ensino de Aritmética deve estar em constante relação com questões cotidianas das crianças e a sala de aula deve funcionar como um grande laboratório. Materiais como "xícaras, copos, garrafas, litros, latas, jarros, caixas próprias para ovos, barbante, fitas de medida e muitos outros objetos que podem ser usados em experiências sobre medida, por exemplo, são de muito fácil aquisição" (PÔRTO, 1965, p. 18).

Pode-se perceber, ao longo do manual, que o aluno está no centro do processo de ensino aprendizagem, que ele deve fazer, manipular objetos, construir suas próprias experiências; à professora cabe o papel de mediadora, como exposto pela autora. "A professora precisa permitir que a criança manipule o material. A criança se interessa pelas idéias quantitativas e pelas relações numéricas, quando pode percebê-las" (PÔRTO, 1965, p. 24). Como podemos perceber, a sala, ao ser utilizada como laboratório, ganha vida e funcionalidade. Com o auxílio da professora, as atividades são organizadas de forma 
cooperativa em grupos, o que demonstra a relação com a escola ativa de Dewey. Essa proposta de ensino defendia que a escola deveria ser atraente, seguir o modelo de uma vida em comunidade, com espaços privilegiados em que os alunos/as aprenderiam as artes e as relações complexas da vida em sociedade. Essa seria uma nova educação, progressista e não passiva, por meio de um ensino que prepara os indivíduos para a vida em sociedade e agindo sobre a sua cultura.

\section{Habilidades de Estudos Sociais}

O manual Habilidades de Estudos Sociais é de autoria da professora primária Maria Onolita Peixoto, que realizou o curso de Orientadora Técnica e Administração Escolar (no Instituto de Minas de Gerais); era Técnica Didática de Estudos Sociais do PABAEE e cursou Educação Elementar na Universidade de Indiana (EUA).

Peixoto discorre que disciplinas como História e Geografia não poderiam ser as únicas fontes para as explicações das relações humanas, que uma vasta quantidade de áreas de conhecimento pode ser somada para contribuir com o entendimento dessas questões. Para a autora, essas disciplinas estavam muito centradas no ensino de memorização de data, lista de nomes de países e capitais, ainda muito vinculados à escola tradicional. Um estudo mais adequado seria encontrado na disciplina de Estudos Sociais, que pretende voltar o ensino para a interação do homem com o meio, da vida em comunidade e das relações sociais e democráticas. De acordo com Peixoto (1965, p. 17):

[...] em Estudos Sociais a intenção é dada aos aspectos e maneiras de vida do homem, ao trabalho de cooperação entre homens, ao uso do ambiente para a satisfação das necessidades básicas; atenta também para aos costumes, as instituições, a herança social, o passado histórico de um povo.

Para apresentar as temáticas de Estudos Sociais, a autora divide o texto em dois grandes capítulos, seguidos da introdução e do texto de apresentação As coisas se constroem porque os homens se unem (texto de apresentação), Habilidades de Estudos Sociais e Habilidades Específicas de Conteúdo e bibliografias. 
No primeiro capítulo, a autora apresenta as habilidades que devem ser desenvolvidas em sala de aula pela professora primária, como dar ideias, ouvir e dar opiniões, dividir objetos, pedir, entre outras atividades. No manual, ela demonstra alguns exemplos de ações que podem ser desenvolvidas pela professora, como Troca de experiência ou Hora da novidade, Planejamento da Professôra e Alunos, Dramatização Espontânea, além de atividades práticas. Todas essas Habilidades de Estudos Sociais estavam muito relacionadas à construção de um modelo de comportamento; um bom aluno, um bom cidadão para a sociedade moderna que caminhava rumo ao progresso, ou seja, o manual é repleto de ensinamentos de comportamentos esperados, tanto por parte dos alunos como também por parte das professoras.

Apenas no segundo capítulo a autora se dedica a demonstrar para a professora os conteúdos específicos a serem trabalhados na disciplina de Estudos Sociais. Esses conteúdos eram sempre identificados como habilidades, e nesse sentido a autora sugere: Como orientar-se a noite; Como orientar pela bússola; Como se orientar pelo relógio; Como ler o globo; Habilidade de leitura de mapa; Habilidade de leitura do globo; Como ler linhas do globo: paralelos e meridianos; Latitude e sua relação com o clima; Latitude e sua relação com o tempo.

A partir desses conteúdos propostos pela autora para a disciplina de Estudos Sociais, fica-nos o questionamento: onde está a proposta de Estudos Sociais e os temas referentes "à vida em comunidade para a sociedade democrática"? Inferimos, de forma preliminar, que há uma dissonância entre a proposta teórica da autora e os conteúdos apresentados para as professoras primárias.

\section{O que é Jardim de Infância}

O manual O que é Jardim de Infância tem como objetivo refletir sobre os problemas básicos acerca do trabalho das professoras no jardim de infância, desde "[...] localização da escola, problemas de tamanho do prédio, equipamento, condições da sala de aula, planejamento de atividades e avaliação" (ABI-SÁBR, 1965, p. 11), em suma, trata da necessidade de equipar os jardins de infância a fim de apresentar uma estrutura compatível com a proposta da escola moderna. 
O manual conta com a autoria de Nazira Féres Abi-Sáber. Ela foi membro do Conselho Estadual de Educação de Minas Gerais, da Organização Mundial do Ensino Primário (OMEP), Técnica de Didática de Educação Pré-Primária do Estado de Minas Gerais e formada pelo Curso de Educação Elementar na Universidade de Indiana (EUA).

Com o objetivo de demonstrar, de forma didática, a importância do jardim de infância, a organização e as atividades a serem elaboradas pelas professoras, a autora organizou o texto com as seguintes temáticas: Os Objetivos do Moderno Jardim de Infância; As Condições Materiais; As Atividades Iniciais; O Ambiente; A Matrícula; Número de Alunos em cada Sala de Aula; O Começo das Aulas; Um dia no Jardim de Infância; Relatórios; Boletins e Fichas de Avaliações; Bibliografias.

No texto Os objetivos do moderno Jardim de Infância, a autora alerta para a forma como o jardim de infância era visto:

\begin{abstract}
Diziam, entre outras coisas, que os institutos de educação pré-primária não passavam de locais onde se "depositavam" os meninos, enquanto as mães iam trabalhar, e as professoras nada mais eram que muito boas "amas-secas", cuja única função consistia em vigiar as crianças enquanto essas brincavam. (ABI-SÁBER, 1965, p. 15)
\end{abstract}

Para a autora, os jardins de infância não recebiam a merecida atenção, começando pela falta destas instituições e pelo não reconhecimento desses espaços como locais de aprendizado no qual as crianças desenvolviam e adquiriam experiências, bem como amadureciam convivendo com outras crianças. "O jardim de infância tem por fim rodear a criança de um ambiente sadio, no qual ela possa viver e conviver bem com os colegas e com todos os membros do grupo, tornando-se, ao mesmo tempo, um bom elemento da sua sociedade" (ABI-SÁBER, 1965, p. 24).

Avançando no texto, a autora fala sobre as condições materiais, e nesse texto chama atenção a riqueza de prescrições sobre a estrutura do jardim de infância. Essas prescrições variam desde a localização do jardim de infância (bairro), à construção do prédio (altura, acústica, cores e acabamentos, posição das janelas e iluminação, ausência de escadas e fiação protegida), além da mobília adequada. 
Figura 01 - Mobiliário para o Jardim de Infância

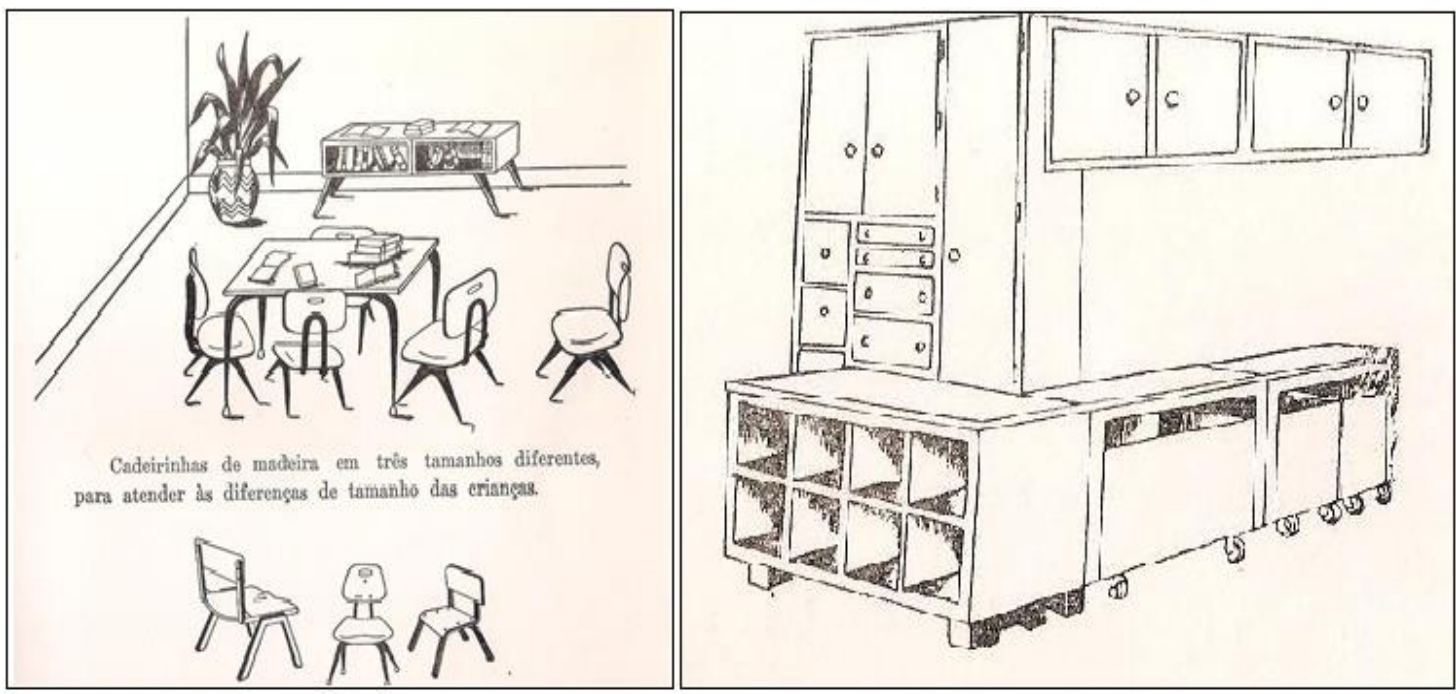

Fonte: Biblioteca de Orientação da Professôra Primária: O que é Jardim de Infância (ABI-SÁBER, 1965, p. 3845).

A autora prescreve sobre a mobília, sugerindo que se invista em mesas retangulares com disponibilidade para seis lugares, mesas específicas para os cantos da sala, onde pode ser organizado um espaço para a leitura. Em relação às cadeiras, elas devem ser de três tamanhos diferentes, adequando-se aos diferentes tamanhos de crianças. Em suma, o texto apresenta um manual prático de como montar um jardim de infância, composto por uma série de indicações para compras de mobiliários e brinquedos, que demonstram o interesse em construir um modelo de jardim de infância moderno no país.

\section{Experiência de Linguagem Oral}

O manual Experiência de Linguagem Oral demonstra a importância da linguagem como instrumento de comunicação na sociedade moderna. "O homem está na permanente dependência dos símbolos verbais e, por êsse motivo, o desenvolvimento da linguagem é elemento essencial a sua perfeita realização, na sociedade em que vive" (ARAUJO, 1965, p. 11).

A autora do manual é Maria Yvone Atalécio de Araujo, professora primária com formação em Orientação Técnica e Administração Escolar pelo Instituto de Minas Gerais, 
também Técnica Didática de Língua Pátria do PABAEE, além de ter realizado o curso de Educação Elementar na Universidade de Indiana (EUA).

O manual é composto por um único capítulo com dezesseis temas, sendo eles: 1- $A$ importância da comunicação oral no mundo moderno; 2 - Ambiente que favorece a expressão oral; 3 - Hábitos; atitudes e habilidades essenciais à comunicação oral; 4 Situações em que se usa a linguagem oral; 5 - Como dirigir conversas e discussões; 6 - As crianças contam histórias e dizem versos; 7 - Dramatizações, pantomimas e fantoches; 8 Poesia e côro falado; 9 - Apresentação de informações orais; 10 - Apresentações e entrevistas; 11 - Instruções anúncios e propagandas; 12 - Programas de auditórios; 13 - Os clubes na escola primária; 14 - O enriquecimento do vocabulário da criança; 15 - Avaliação, correção e desenvolvimento continuo da linguagem e Bibliografia.

Podemos perceber ao longo dos tópicos que a autora apresenta diferentes atividades que compõem um leque de estratégias para a professora primária desenvolver em sala de aula com seus alunos. Mais uma vez, chama atenção a importância dada à mobília e à organização da sala. Sobre isso, a autora questiona: "Como se poderia manter uma conversa animada, estando os interlocutores de costas viradas uns para os outros? Ou, de que modo a classe se empenharia em discussão, num ambiente formal e rígido?" (ARAUJO, 1965, p. 26). Observam-se, assim, as críticas que o programa faz a metodologias mais tradicionais, aos modelos de sala de aula compostos por filas, em que o professor está geralmente à frente da turma, representando a centralidade do processo escolar.

A presença destes manuais nos informa como deveria ser esse cotidiano da escola e das sala de aulas: repleta de prescrições e instruções detalhadas, a coleção de manuais Biblioteca de Orientação da Professôra Primária é uma importante fonte de pesquisa para entendermos a história da educação brasileira.

\section{Algumas considerações}

Promover a melhoria dos índices educacionais brasileiros, realizar o aperfeiçoamento de professores/as, formar alunos/as para uma sociedade moderna constituía alguns dos pontos centrais do discurso governamental sobre a educação que 
se desejava para o desenvolvimento do país, nos anos de 1950 e 1960. Imbuídos desse discurso, surgem diversas campanhas educacionais que tinham como objetivo reverter um quadro problemático da educação brasileira. Nesse contexto, o PABAEE é apresentado como uma solução para os diversos problemas educacionais da época.

Para atingir esses propósitos, o PABAEE se centrou em dois objetivos principais: no aperfeiçoamento dos professores/as e na produção de materiais didáticos que serviria de aporte para o trabalho da professora primária. A criação da coleção de manuais intitulada Biblioteca de Orientação da Professôra Primária veio nesta direção com o intuito de reunir, organizar e prescrever os conteúdos e as habilidades que deveriam ser incorporadas nas práticas pedagógicas das professoras primárias e, consequentemente, por seus/suas alunos e alunas. Assim, esses manuais deveriam ser utilizados como verdadeiros guias para o trabalho cotidiano da professora na medida em que a ensinava a atuar nas diferentes áreas, prescrevendo conteúdo, material didático, comportamentos, estrutura e organização da sala de aula.

O PABAEE alcançou uma vasta abrangência no território nacional, atingindo 25 estados brasileiros, nos quais foram realizados os cursos de aperfeiçoamento e possivelmente esses manuais acabaram circulando. Nesse sentido, concordamos com Saturnino (2005), ao considerar que os materiais culturais, como os manuais escolares aqui analisados, não circulam em um campo restrito a públicos específicos, percorrem caminhos diversos, espalham-se e propagam-se, muitas vezes adquirindo novos significados. Ou seja, para além da prescrição, ocorriam as críticas e as adaptações. Além disso, os manuais também podem ser analisados por um conjunto de fatores, inclusive de ordem econômica.

A coleção de manuais, além do financiamento do governo brasileiro, contou também com auxílio dos técnicos norte-americanos, afinal, todas as professoras autoras receberam formação na Universidade de Indiana (EUA).

Ao analisar a coleção, foi possível identificar alguns aspectos que demonstram que havia um projeto educacional, um currículo e diversas orientações de como fazer. Além de apresentar os conteúdos, as autoras demonstravam como deveria ser a escola, qual a forma adequada de organizar a sala, os tipos de mobiliários, os exemplos de atividades, as ilustrações com o passo a passo de como fazer e que modelo de alunos/as pretendia-se 
construir. Ao que tudo indica, essas questões estavam vinculadas a uma proposta educacional que visava a um ensino mais prático e preparatório para a vida em sociedade, ficando evidentes, em muitos momentos, as críticas à escola tradicional.

Estudar cada manual da coleção talvez nos ajude a compreender as permanências e rupturas ocorridas nas práticas pedagógicas da escola primária brasileira. Cada manual contém um conjunto de informações a serem exploradas, problematizadas à luz de diferentes perspectivas. Inúmeras perguntas podem ser lançadas a estes manuais ao tratá-los como documentos, uma vez que, segundo Le Goff (2003, p.545), “o documento não é qualquer coisa que fica por conta do passado, é um produto da sociedade que o fabricou segundo as relações de força que aí detinham o poder". Nessa perspectiva, a coleção permite inúmeros olhares e interpretações.

Cumprido o propósito de apenas apresentar a coleção Biblioteca de Orientação da Professôra Primária, esperamos que estes sejam o lócus de muitas pesquisas no campo da educação e da história da educação, pois entendemos que o manual escolar permite realizar inúmeras aproximações.

Os manuais e a coleção apresentam-se como testemunhos vivos dos métodos e concepções pedagógicas do período desenvolvimentista no país. Ajudam-nos a compreender os discursos que circulavam na época para o desenvolvimento do país e como esses ressoavam no setor educacional. 


\section{Referências}

ABI-SÁBER, Nazira Féres. O que é jardim de infância - Programa de Assistência BrasileiroAmericana ao Ensino Elementar - Belo Horizonte. Rio de Janeiro: Editora Nacional de Direito, RJ 1965.

ARAUJO, Maria Yvone Atalécio. Experiência de linguagem oral - Programa de Assistência Brasileiro-Americana ao Ensino Elementar - Belo Horizonte. Rio de Janeiro: Editora Nacional de Direito, 1965.

BERUTI, Maria José; NARDELLI, Terezinha. Ciências na Escola Moderna - Programa de Assistência Brasileiro-Americana ao Ensino Elementar - Belo Horizonte. Rio de Janeiro: Editora Nacional de Direito, 1965.

BLACK, Lloyd D. A estratégia de ajuda externa. Tradução de Carlos Nayfeld. Rio de Janeiro: O Cruzeiro, 1968.

CHOPPIN, Alain. O manual escolar: uma falsa evidência histórica. Tradução: Maria Helena C. Bastos. História da Educação. Pelotas: ASPHE/FaE/UFPel, v. 13, n. 27 p. 9-75, jan./abr., 2009.

DAROS, Maria das Dores; Leziany Silveira Daniel e Ana Claudia da Silva. Identidade social do professor Fontes Históricas: contribuições para o estudo da formação de professores catarinenses (1883-1946). Florianópolis: NUP/CED/UFSC. 2005. 133p.

CHARTIER, Roger. O mundo como representação. In: CHARTIER, Roger. À beira da falésia: a história entre incertezas e inquietude. Trad. Patrícia Chittoni Ramos. Porto Alegre: Ed. Universidade/UFRGS, 2002, p. 61-80.

ESTEVES, Oyara Petersen. Testes, medidas e avaliação - Programa de Assistência Brasileiro-Americana ao Ensino Elementar - Belo Horizonte. Rio de Janeiro: Editora Nacional de Direito, 1965.

FERREIRA, Maria Luíza de Almeida Cunha. Formação e desenvolvimento de conceitos Programa de Assistência Brasileiro-Americana ao Ensino Elementar - Belo Horizonte. Rio de Janeiro: Editora Nacional de Direito, 1965.

GALVÃO, Ana Maria de Oliveira; BATISTA, Antonio Augusto Gomes. Manuais escolares e pesquisa em história. In: VEIGA, Cynthia Greive; FONSECA, Thais Nívia de Lima (Orgs). História e historiografia no Brasil. Belo Horizonte: Autêntica, 2003, p. 161-188.

LE GOFF, Jacques. Memória e história. São Paulo: Unicamp, 2003.

LOURO, Guacira Lopes. Mulheres na sala de aula. In: DEL PRIORE (Org.). História das mulheres no Brasil. São Paulo: Contexto, 2008. p. 443-481. 
MARTINNS, Ângela Maria Souza. Dos anos dourados aos anos de zinco: análise histórico cultural da formação do educador no Instituto de Educação do Rio de Janeiro. 1996. Tese (Doutorado em Educação) - Universidade Federal do Rio de Janeiro, Rio de Janeiro, 1996.

PAIVA, Edil Vasconcellos de; PAIXÃO, Lea Pinheiro. PABAEE (1956 - 1964): a americanização do ensino elementar no Brasil? Niterói: EdUFF, 2002.

PEIXOTO, Maria Onolita. Habilidades de estudos sociais na escola primária - Programa de Assistência Brasileiro-Americana ao Ensino Elementar - Belo Horizonte. Rio de Janeiro: Editora Nacional de Direito, 1965.

PÔRTO, Rizza Araújo. Ver, sentir e descobrir aritmética - Programa de Assistência Brasileiro-Americana ao Ensino Elementar - Belo Horizonte. Rio de Janeiro: Editora Nacional de Direito, 1965.

SATURNINO, Edison Luiz. Imagem, memória e educação: um estudo sobre modos de ver e lembrar. 2005. Universidade Federal do Rio Grande do Sul. Faculdade de Educação. Programa de Pós-Graduação em Educação. Disponível em: <http://www.lume.ufrgs.br/handle/10183/6679>. Acesso em: 02 mar. 2017.

SAVIANI, Dermeval. A nova lei da educação: trajetória, limites e perspectivas. Campinas: Autores Associados, 1997.

SAVIANI, Dermeval. As concepções pedagógicas na história da educação brasileira: texto elaborado no âmbito do projeto de pesquisa "O espaço acadêmico da pedagogia no Brasil", financiado pelo CNPq, para o "projeto 20 anos do Histedbr". Campinas, 25 de agosto de 2005.

SAVIANI, Dermeval. Formação de professores: aspectos históricos e teóricos do problema no contexto brasileiro. Revista Brasileira de Educação. Campinas: Universidade Estadual de Campinas, Faculdade de Educação, v. 14 n. 40 jan./abr. 2009.

SILVA, Gaspar da Vera. Lucia; PETRY, Marilia Gabriela. (Orgs.). Objetos da escola: espaços e lugares de constituição de uma cultura material escolar (Santa Catarina - séculos XIX e XX). Florianópolis: Insular, 2011.

XAVIER, M. (Org.). História da educação: a escola no Brasil. São Paulo: FTD, 1994.

Recebido em: 16/05/2017 Aprovado em: 26/06/2017

Universidade do Estado de Santa Catarina - UDESC Programa de Pós-Graduação em Educação - PPGE

Revista Linhas

Volume 19 - Número 39 - Ano 2018 revistalinhas@gmail.com 